\title{
A Bibliometric Study of Authorship and Collaboration Trends over the Past 30 Years in
}

\section{Four Major Musculoskeletal Science Journals}

\author{
Arielle F. Russell ${ }^{1}$ B.S. \\ Randall T. Loder ${ }^{1}$ M.D. \\ Andrew S. Gudeman ${ }^{1}$ B.S. \\ Peter Bolaji ${ }^{1}$ M.S. \\ Piiamaria Virtanen ${ }^{1}$ B.S. \\ Elizabeth C. Whipple ${ }^{2}$ M.L.S. \\ Melissa A. Kacena ${ }^{1}$ Ph.D. \\ ${ }^{1}$ Department of Orthopaedic Surgery, Indiana University School of Medicine, Indianapolis, IN, US \\ ${ }^{2}$ Ruth Lilly Medical Library, Indiana University School of Medicine, Indianapolis, IN, US
}

This work was supported in part by the Department of Orthopaedic Surgery, Indiana University School of Medicine

(MAK, RTL), the Garceau Professorship Endowment and Rapp Pediatric Orthopaedic Research Fund, Riley

Children's Foundation (RTL), and the Ruth Lilly Medical Library (ECW). This work was also supported by the

Ralph W. and Grace M. Showalter Research Trust (MAK).

Address all correspondence to:

Randall T. Loder, MD

Riley Children's Hospital, ROC 4250

705 Riley Hospital Drive

Indianapolis, IN 46202

317-948-0961

FAX 317-944-7120

rloder@iupui.edu

\begin{abstract}
AF Russell
RT Loder

AS Gudeman

P Bolaji

P Virtanen

EC Whipple

MA Kacena
\end{abstract}

ORCID ID Number 0000-0002-5165-3824 0000-0003-1217-0528 0000-0002-8138-0660 0000-0002-3406-1659 0000-0002-1006-6009 0000-0002-0103-6318 0000-0001-7293-0088

This is the author's manuscript of the article published in final edited form as: 


\begin{abstract}
This study explored changes in bibliometric variables over the last 30 years for four major musculoskeletal science journals $\left(B O N E \circledast\right.$, Calcified Tissue International $\left.{ }^{(C T I}\right)$, Journal of Bone and Mineral Research $(J B M R \circledast)$, and Journal of Orthopaedic Research ${ }^{\circledR}(J O R \circledR)$, with a specific focus on author gender. Bibliometric data was collected for all manuscripts in 1985(BONE®, CTI®, JOR®), 1986(JBMR®), 1995, 2005, and 2015; 2,776 manuscripts met inclusion criteria. Manuscripts from Europe were more often published in $B O N E \circledast$ or $C T I ®$, while those from North America in $J B M R \circledR$ or $J O R \circledR$. All journals demonstrated an increase over time in the number of authors (3.67 to 7.3), number of countries (1.1 to 1.4), number of institutions (1.4 to 3.1), and number of references (25.1 to 45.4). The number of manuscript pages increased (6.6 to 8.9) except for $J O R \circledR$ which showed a decline. $C T I ®$ had the lowest number of authors ( 4.9 vs. 5.6 to 6.8 ). There was a change in the corresponding author position from first to last for all journals; this change was highest for $C T I \circledR(35 \%)$ and lowest for BONE® (14.0\%). All journals demonstrated an increase over time in female authors; however, $C T I \circledR$ was the highest amongst these four journals. The percentage of female first authors rose from 24.6 to $44.3 \%$ (CTI® 29.1 to $52.3 \%$ ). The percentage of corresponding female authors rose from 17.5 to $33.6 \%$ (CTI® 22.9 to $40.0 \%$ ). The proportion of female authors is increasing, likely reflecting the increasing number of women obtaining doctorates in science, medicine, and engineering.
\end{abstract}

Keywords Gender • Authorship trends $\bullet$ Bibliometrics $\bullet$ Geographic region $\bullet$ Time $\bullet$ Musculoskeletal 


\section{Introduction}

In recent years, women have been accepted to undergraduate and graduate education programs at similar rates as men [1,2]. The fraction of women gaining doctorates in science has more than doubled in the United States since 1980 and is now nearing equity. In 2011, 54\% of US doctorates in molecular biology were women compared to $31 \%$ in philosophy [3]. In some European countries, women outnumber men in science degrees but there is significant variation between nations and fields [1]. In Europe, women science and engineering doctorate students are less likely than men to be employed in highly ranked universities, even after controlling for their research outputs [4]; women also fail to reach top leadership positions in all of academia compared to the political arena [5]. Female representation among science and engineering faculty members in the US lags behind the gains in graduate education. Their progression to higher faculty ranks is diminished behind that of their male counterparts, in part because many women do not apply for tenure-track jobs [2], even though a study of US science departments showed that women were more successful than men in gaining tenure between 2002 and 2004. In Europe as in the US, the gender gap is greater among senior compared to junior faculty members [1]. In medicine in the US, women comprise $47 \%$ of medical school enrollment, but only $15 \%$ of clinical faculty [6]. Female representation in basic science departments of medical schools is lower than that compared to other university science departments [7].

Manuscript publications are a major prerequisite for academic advancement. Decisions on admissions, promotions, and grant funding are often contingent on the researchers" publication history $[8,9]$. A "gender gap" in authorship in science overall as well as high profile medical journals $[10,11]$ is well known. There is also a gender gap in successful research funding across all of academia $[12,13]$. However, gender differences in publication rate and impact are highly variable by discipline across academia $[14,15]$. There is little data regarding this topic in musculoskeletal science research, and how it might be changing over time. This may be due to a bias against such research [16] or that it has not been done, either of which may explain this lack of information. Information regarding this question is important to have, which could afford senior faculty/scientists the ability to better guide and mentor junior learners at the undergraduate, graduate/professional school, and junior faculty levels. For this reason, we wished to investigate authorship gender trends across four major musculoskeletal science journals: BONE®, Calcified Tissue International ${ }^{\circledR}(C T I \circledR)$, Journal of Bone and Mineral Research $\left.{ }^{(J B M R} 囚\right)$, and the Journal of Orthopaedic Research ${ }^{\circledR}(J O R \circledast)$. The detailed data for three of the four journals $(B O N E \circledast, J B M R \circledast$, and $J O R \circledR$ ) has been previously published [17-19]; the reader is directed to those manuscripts for detailed results. That data is from the same group of researchers and senior authors as the $C T I \circledR$ data; thus, we were able to use the raw data for comparison purposes in this manuscript. In this manuscript we present the detailed data for $C T I @$ as well as comparisons between the four journals.

At the same time, efforts are also being made to promote collaboration within the scientific community. The scientific community has traditionally been guarded due to the competition between institutions for publications, funding, and scientific discovery. However, advancements in technology and the value in team science [20] have opened the doors for multiple institutions to contribute to one project or end goal [21]. Utilizing the strengths of each participating institution or department can result in a product far superior than what would be achieved individually. It is also known that there have been many changes over time in medical/scientific publications for 
various bibliometric variables, such as the number of authors, manuscript length, and number of references.

Therefore, we wished to also investigate changing trends in bibliometric variables and collaboration over the last 30 years across/between these same four major journals.

Methods

A bibliometric analysis of the past 30 years of all four journals publications was performed. The same method of analysis was performed for all four journals. The most recent year chosen for analysis was 2015 , as this was the first year with complete data available via PubMed as our study began in 2016. Each decade was analyzed by collecting data in 10-year intervals (1985/1986, 1995, 2005, and 2015) (1986 was used for JBMR® as that was its first year of publication, and 1985 for the other journals). This bibliometric method of selecting years separated by a decade has been previously validated [10, 17]. After completing a PubMed search, editorials, letters, and commentaries were excluded. The citations were downloaded into EndNote X7'TM (Clarivate Analytics, Philadelphia, PA, 2013). Using this software, memorandums, meeting notes, meeting abstracts, and entries without authors were identified and excluded. Electronically published articles that were not printed until the following year were also deleted. After the exclusions had been completed, the data was downloaded into a Microsoft Excel ${ }^{\mathrm{TM}}$ (Redmond, WA, 2013) file for further manipulations.

The names of first and corresponding authors; corresponding author position (first, second, last, other, as well as the numerical position in the byline of all authors); country of origin (corresponding author) and state or province for publications from the US or Canada, respectively; number of institutions, countries, authors, printed pages, and references were tabulated. Author gender was identified for the first and corresponding authors using the "Baby Name Guesser" (http://www.gpeters.com/names/baby-names.php) method described by Mimouni et. al. [22]. The author's first name was entered into the baby name guesser, and a gender along with a gender ratio was obtained that results in a male/female gender. A ratio at or above 3.0 was chosen as a correct gender [22]. If the ratio was less than 3.0, a Google search was used to assign gender; if such a search could not ascertain the gender, it was excluded for any gender-based analyses. Countries were grouped by regions. North America was designated as the United States of America and Canada; Mexico, Central America, and South America as Latin America; the European continent including Russia and Turkey as Europe; and Asia as all Asian countries beginning east of Turkey, including the Middle East and Israel. The other regions were Africa and Australia/New Zealand. The number of times each publication was cited was analyzed as one proxy of research controversy/popularity. Citation data was obtained from a Scopus search during August 2016. Since more recent publications have a lesser chance of being cited, the citation values were recalculated to citations per year of manuscript by dividing the number of citations by the age in years of the manuscript ( 1 for 2015, 11 for 2005, 21 for 1995, 30 for 1986, and 31 for 1985).

\section{Statistical Analyses}

Continuous data are reported as the mean \pm 1 standard deviation and discrete data as frequencies and percentages. Analyses between groups of continuous data were performed using non-parametric tests due to the data having non-normal distributions (Mann-Whitney $\mathrm{U}-2$ groups; Kruskal-Wallis test -3 or more groups).

Differences between groups of discrete data were analyzed by the Fisher's exact test ( 2 × 2 tables) and the Pearson's $\chi^{2}$ test (greater than $2 \times 2$ tables). For $2 \times \mathrm{k}$ tables the Cochran linear trend test (CLT) was used to assess for an 
ordering effect of the $\mathrm{k}$ variables. Logistic regression analysis was used to determine predictor variables of female first authorship, female corresponding authorship, and both female first and corresponding authorship, with resultant odds ratios (OR), 95\% confidence intervals [CI] of the OR, and associated $p$ values. For all statistical analyses a $p<$ 0.05 was considered statistically significant. Statistical analyses were performed with Systat $10^{\mathrm{TM}}$ (Systat Software, Chicago, IL, 2000).

Analysis of the corresponding author position were performed using several methods for both continuous and categorical data. For using continuous data, the simplest analysis is to use the numerical position of the corresponding author in the byline of all authors. However there has been an increase in author number over time. This can be adjusted by dividing the author numerical position by the total number of authors creating a standardized author position. When using categorical data, the location of the corresponding author can be classified as first, second, last, or other.

\section{Results}

In this study we report the detailed results for $C T I ®$ as well as comparisons between all four journals. There were 2,901 total citations obtained from the PubMed search for all four journals. After review, there were 125 exclusions; 33 for $B O N E \circledast$, 20 for $C T I \circledR, 63$ for $J B M R \circledast$, and 9 for $J O R \circledast$. Thus 2,776 manuscripts met inclusion criteria: 899 from $B O N E \AA$, 514 from $C T I \circledR, 764$ from $J B M R \AA$, and 617 from JOR®. The average author number was 5.8 \pm 3.0 , number of countries $1.3 \pm 0.8$, and number of institutions $2.4 \pm 1.8$ (Table 1). For author number, $C T I ®$ was the lowest $(4.9 \pm 2.4)$ compared to JOR® $(5.6 \pm 2.5)$, BONE® $(5.8 \pm 3.0)$, and $J B M R \circledast(6.8 \pm 3.5)\left(p<10^{-6}\right)$.

This remained consistent by year of publication, author gender (first and corresponding), and region. The number of authors increased over time, from 3.6 \pm 1.7 in 1985/1986 to $7.3 \pm 3.5$ in 2015; this trend occurred across all four journals (all $p<10^{-6}$ ). The number of collaborating countries was the lowest for $C T I \circledast$ and JOR® (both 1.2 \pm 0.5 ) compared to $B O N E \circledast(1.3 \pm 0.8)$ and $J B M R \circledast(1.4 \pm 1.0)(p=0.000001)$. All journals demonstrated a gradual increase in the number of collaborating countries over time. Due to the limited number of manuscripts from Africa (5) and Latin America (26) they were excluded from further analyses unless otherwise indicated. Manuscripts originating from Europe had the highest number of countries (1.4 \pm 1.0$)$ compared to Australia/New Zealand (1.3 \pm 0.5$)$, North America (1.2 \pm 0.7$)$, and Asia $(1.2 \pm 0.6)\left(p<10^{-6}\right)$. There were no differences in the number of countries by either first or corresponding author gender. The number of involved institutions was highest for $J B M R \bowtie(2.7 \pm 2.3)$, followed by $B O N E \circledast(2.4 \pm 1.7), J O R \circledast(2.3 \pm 1.4)$, and $C T I \circledR(2.0 \pm 1.4)\left(p<10^{-6}\right)$, and remained constant by author gender and region except for those originating from Australia/New Zealand. There was an increasing number of institutions over time, moving from $1.4 \pm 0.7$ in $1985 / 1986$ to $3.1 \pm 2.3\left(p<10^{-6}\right)$; this pattern was consistent for all four journals. Manuscripts originating from Europe and Australia/New Zealand had the highest number of institutions (2.5 \pm 2.0 and 2.5 \pm 1.4 respectively), followed by Asia (2.4 \pm 1.6$)$ and North America $(2.2 \pm 1.8)(p=0.0002)$.

The average number of number of pages was 7.8 \pm 2.6 , references $37.8 \pm 21.1$, and number of citations per year 3.3 \pm 4.3 (Online Resource 1). The number of pages was highest for $J B M R \circledast(8.6 \pm 2.6$ ), followed by $J O R \circledR$ (8.0 \pm 2.4$)$, BONE® $(7.7 \pm 2.5)$, and $C T I \circledast(6.7 \pm 2.8)\left(p<10^{-6}\right)$. There was an increase over time in the number of pages for all journals, from $6.6 \pm 2.7$ in 1985/1986 to $8.9 \pm 2.7$ in $2015\left(p<10^{-6}\right)$; this pattern was seen in all of the journals, except for $J O R \circledR$ where it dropped from 8.6 \pm 3.2 to $8.3 \pm 2.9(p=0.000003)$. Manuscripts with female first or 
corresponding authors had a slightly higher number of pages than those with male first or corresponding authors (first author $8.1 \pm 2.7$ vs. $7.7 \pm 2.6, p=0.00004$; corresponding author $8.1 \pm 2.7$ vs. $7.7 \pm 2.6, p=0.003$ ), and remained constant across journals. Those manuscripts originating from Europe had lowest number of pages (7.6 \pm 2.6$)$

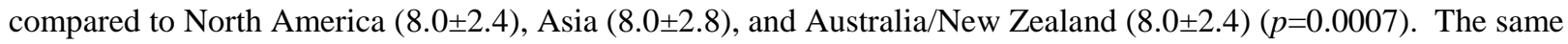
trend persisted for all of the journals except for $B O N E \circledast$, where the page number was essentially equal for all four regions ( 7.7 to $7.9, p=0.48)$. The number of references was highest for $B O N E \circledast(41.4 \pm 26.6)$, followed by $J B M R \circledR$ (40.8 \pm 18.8$), J O R \circledast(33.7 \pm 14.0)$, and $C T I \circledast(31.7 \pm 18.4)$. The number of references increased for each decade, going from $25.1 \pm 13.1$ in 1985/1986 to $45.4 \pm 27.6$ in 2015; this increase occurred across all four journals $\left(p<10^{-6}\right)$. Manuscripts with female first or corresponding authors had approximately three more references than those with male first or corresponding authors (first author - male 36.6 \pm 20.5 , female 39.7 $\pm 22.4 ; p=0.000009$; corresponding author -male 36.9 \pm 21.0 , female $40.0 \pm 21.8, p=0.000004$ ). This remained true for first authors in $B O N E \circledast$ but for none of the other journals. For corresponding authors, it held true for $B O N E \circledast$ and $J B M R \circledR$, but not $C T I \circledR$ or $J O R \circledast$. The number of references was slightly less for manuscripts originating from Asia (35.2 \pm 15.3$)$ compared to Europe (37.4 \pm 22.4$)$, North America (38.4 \pm 21.6$)$, and Australia/New Zealand (41.0 \pm 24.3$)(p=0.044)$. However, when breaking down by each journal, there were no differences in the number of references by region. The number of

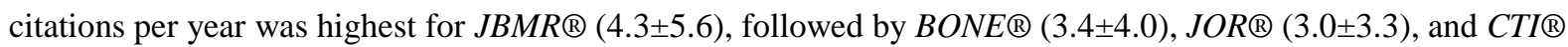
$(2.1 \pm 2.8)\left(p<10^{-6}\right)$. This pattern remained the same when analyzing by year, gender, and region. The number of citations per year increased over time for all journals from 1995-2005. Within journals there were no differences by author gender or region in the number of citations per year. The number of citations per year was slightly higher for

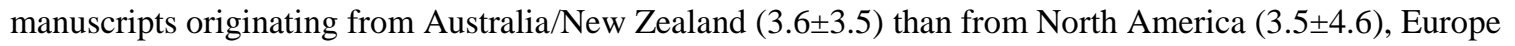
(3.3 \pm 4.4$)$, or Asia $(2.7 \pm 2.8)(p=0.038)$

\section{Single Author Manuscripts}

Single authorship occurred in $70(2.6 \%)$ of the manuscripts and ranged from $1.2 \%$ for JOR® to $4.6 \%$ for $C T I \circledR(p=0.000003)$. For these 70 single author manuscripts, the author was male in 57 manuscripts $(81.4 \%)$ compared to the multi-author manuscripts where the first author was male in 64.9\% ( $p=0.003)$. The percentage of single author manuscripts decreased markedly over time from $6.5 \%$ to $0.9 \%$ for all four journals $\left(p<10^{-6}\right)$.

\section{Corresponding Author Position/Location}

When excluding single author manuscripts, the average actual and standardized corresponding author position for all four journals was $3.3 \pm 2.7$ and $0.58 \pm 0.38$ respectively. There were significant differences by decade, journal, first and corresponding author gender, and region (Online Resource 2). The actual corresponding author position increased by decade from $1.7 \pm 1.4$ in $1985 / 1986$ to $4.7 \pm 4.1$ in $2015\left(p<10^{-6}\right)$, and the standardized position from $0.48 \pm 0.30$ in $1985 / 1986$ to $0.65 \pm 0.40$ in 2015 ( $p=0.00002)$. $C T I ®$ had the highest actual position $(4.9 \pm 2.4)$ and $B O N E \circledast / J O R \circledast$ the lowest $(3.2 \pm 3.1,3.2 \pm 2.9)\left(p<10^{-6}\right)$. However, there were no differences by journal for the standardized position. Female first authors had both a higher actual and standardized position $(6.2 \pm 3.2$ and $0.61 \pm 0.39$, respectively) than male first authors (5.6 \pm 3.0 and $0.56 \pm 0.38$, respectively) (actual: $p=0.000005$, standardized: $p=0.011$ ). For female corresponding authors there were no overall differences in the actual position, but females were lower in the standardized position (female: $0.53 \pm 0.38$, male: $0.60 \pm 0.38, p=0.00003$ ). Manuscripts 
originating from Europe had the lowest actual position (2.9 \pm 3.2$)$ and from Asia the highest $(4.1 \pm 3.8)\left(p<10^{-6}\right)$; for the standardized position, those from Europe had the lowest $(0.50 \pm 0.38)$ and North America the highest $(0.64 \pm 0.38)$ $\left(p<10^{-6}\right)$.

There were significant differences in corresponding author location by year, journal, region, and author gender (all $p<0.001$ ) (Fig. 1). Most noticeable was the rapid change over time moving from first to last author. There were very few second or other positions, and when the data was reanalyzed using only the first or last author position, as done by others [23], the differences all remained highly significant: year $p<10^{-6}$, journal $p=0.00003$, region $p<10^{-6}$, first author gender $p=0.00002$, corresponding author gender $p=0.0005$, and number of authors $p<10^{-6}$.

Finally, we studied the corresponding author position relative to the number of authors on the manuscript [24]. There were 2,684 manuscripts having greater than one author and where the corresponding author position was known. The number of authors ranged from 2 to 27 ; however, the vast majority $(2,512$, or $93.6 \%)$ had 10 authors or less. As the number of authors increased, the corresponding author position moved more from first to last (Fig. 1d) $\left(p<10^{-6}\right)$. This same phenomenon was seen for North America $(p=0.000001)$, Asia $(p=0.0001)$, BONE® $(p=0.0019), C T I \circledast(p=0.0004), J O R \circledast(p=0.009)$, male and female first authors $(p=0.0003$ and 0.00007 , respectively), and male and female corresponding authors ( $p<10^{-6}$ and $p=0.036$, respectively). It was not seen for Australia/New Zealand $(p=0.055)$, Europe $(p=0.084), J B M R \circledast(p=0.094)$, or within any of the year groups (Online Resource 3). The greatest change from first to last position was for $C T I \circledR(35.0 \%)$ and the least for BONE® $(14.0 \%)$.

\section{Analyses by Region}

There were 1,363 manuscripts from North America, 859 from Europe, 397 from Asia, 124 from Australia/New Zealand, 27 from Latin America, and 5 from Africa. Due to the small numbers from Latin America and Africa, they were deleted for the purposes of regional analyses. Manuscripts from Europe were more often published in $B O N E \circledast$ or $C T I \circledR$, while those from North America in $J B M R \circledR$ or $J O R \circledR$ (Fig. 2a). Within Canada, the four most common provinces were Ontario (47.0\%), Quebec (26.9\%), Alberta (11.9\%), and British Columbia (11.2\%), with significant differences between journals (Fig. 2b). Within the US, the four most common states were California (15.6\%), New York (10.9\%), Massachusetts (9.0\%), and Pennsylvania (6.9\%) with no significant differences by journal (Fig. 2c). There were no differences over time between these four most common states. Within Europe, the four most common countries were the United Kingdom (21.3\%), France (11.8\%), Germany (11.8\%), and Italy (8.7\%), with significant differences between journals (Fig. 2d), and over time, with Italy and Germany publishing more manuscripts in the last two decades (Online Resource 4). Within Asia, the four most common countries were Japan (54.4\%), China (19.5\%), Korea (8.4\%), and Israel (7.8\%), with significant differences between journals (Fig. 2e). When analyzing only those from Japan and China, there was a significant change over time in the percentage from each country. In 1985/1986, 6.7\% of all the manuscripts originated from China and 93.3\% from Japan. By 2015, the percentages were 47.7\% for China and 52.3\% for Japan $\left(p<10^{-6}\right)$. This China/Japan trend persisted for all four journals. For the 27 manuscripts from Latin America, 17 were from Argentina, 9 from Brazil, and 1 from Chile. All 5 from Africa originated from South Africa. Online Resource 4 gives the detailed data and graphs showing changes over time. 


\section{Analyses by Author Gender and Gender Combinations}

There was a significant increase in both female first and corresponding authors over time (Figs. 3a and 3b) which remained constant for all journals (Online Resource 5). Although JOR® showed the greatest increase in female authors, $C T I{ }^{\circledR}$ consistently had the highest percentage of female authors (Fig. 3). This increase over time also held true by regions. The greatest increase in female first authors was $25.0 \%$ for Australia/New Zealand and $24.6 \%$ for Europe, compared to $20.4 \%$ for North America and $8.1 \%$ for Asia. The greatest increase in female corresponding authors was $22.1 \%$ for Australia/New Zealand, followed by Europe (20.9\%), Asia (14.9\%), and North America (14.3\%). These changes over time were all statistically significant $(p<0.05)$.

There are four possible gender combinations between the first and corresponding authors; both authors male (MM), first author male and corresponding author female (MF), first author female and corresponding author male (FM), and both authors female (FF). Manuscripts where the corresponding and first author were the same were excluded. There were significant changes in the author gender combinations and all changed significantly over time (Fig. 4a), by journal (Fig. 4b), and by region (Fig. 4c) (all $p<0.0001$ ).

The results of multivariate logistic regression are shown in Table 2. The odds ratio (OR) for a female first author was highest for $C T I ®$ (2.52), followed by $J B M R \circledast,(2.23)$, and $B O N E \circledast$ (2.08) with $J O R \circledast$ as the reference; Australia/New Zealand (2.33), followed by North America (2.22), and Europe (2.21) with Asia as the reference; and year 2015 (2.91), year 2005 (1.79), year 1995 (1.16) with 1985/1986 as the reference. The OR of a female corresponding author was highest for $C T I \circledR$ and $J B M R \circledast$ (2.03 and 2.06), Europe and Australia/New Zealand (2.62 and 2.59), and year 2015 (2.66). The OR of both authors being female was highest for $C T I ®$ (2.40), Australia/New Zealand (3.42), and year 2015 (2.16).

\section{Discussion}

There are certain limitations to this study. First, journals have different life stages. Some journals are newer, and others are older and therefore it is difficult to compare them. However, all four of the journals are recent (CTI® - 1967, BONE® - 1978, JOR® - 1983, JBMR® - 1986), compared to other major science journals (Nature 1869, Science - 1880, Proceedings of the National Academy of Sciences -1915). Thus, the effect of different life stages on our results is likely small. Another limitation is that our study was an analysis of one year per decade, not analyzing every year. The ideal study would be to include every year; however, such a bibliometric study is resource intensive and very difficult to carry out. However, the decade approach is a very accurate assessment giving essentially similar results compared to an every year sampling approach [17]. Another limitation is that not all corresponding authors are the senior investigator, although that is often true [23, 25-28]. A final weakness might be that some of the differences are statistically, but not meaningfully, significant (eg. number of collaborating countries over time). To not bias the reader, all data and statistical analyses are provided so that the reader can review the data and draw their own conclusion regarding meaningful differences.

It is well known that there has been an increasing number of authors on manuscripts over time [29]. This can be interpreted different ways. It may represent increased collaboration [30-32] and advancements in technology [21]. However, it may also represent an inflationary process with other explanations such as honorary authorship or studies from large teams where many team members are given authorship even though there was little or no 
contribution to the study [33]. The prevalence of ghost/honorary authorship has been estimated to be $21 \%$ in even the most influential medical journals [33]. Using 2-3 authors per article as baseline, 4-6 coauthors increased the chance of honorary authors 3.5 fold; $7-10$ by 7.9 fold, and 11 or more by 10.8 fold [34]. It is postulated that power asymmetry among co-authors gives rise to this phenomenon. Some senior researchers often simply read the manuscript of their junior colleagues, and by approving it, feel entitled to be an author [35]. Today most journals require an ethical statement outlining all authors' contributions to minimize this issue. In this present study the

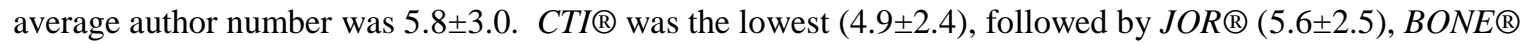
(5.8 \pm 3.0$)$, and $J B M R \circledast(6.8 \pm 3.5)$. However, these numbers are very small compared to other disciplines, such as high energy physics [36], where there is "hyperauthorship", often with 200 to 600 authors on a single study. Thus, the musculoskeletal science research field appears to be less affected by rapid authorship inflation, with $C T I ®$ having the lowest number of authors overall.

There appears to be increasing collaboration in the manuscripts published within these four journals over time. The number of institutions increased from $1.4 \pm 0.7$ in 1985/1986 to 3.1 \pm 2.3 in 2015 and occurred with all four journals (Fig. 5a). Manuscripts originating from Europe and Australia/New Zealand had the highest number of

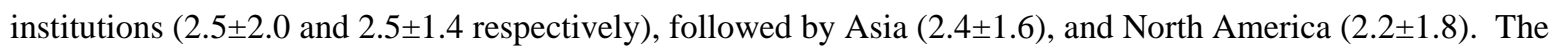

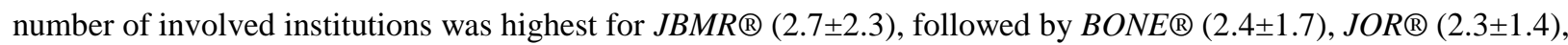
and $C T I \circledR(2.0 \pm 1.4)$. Manuscripts originating from Europe had the highest number of countries (1.4 \pm 1.0$)$ compared to Australia/New Zealand (1.3 \pm 0.5 ), North America (1.2 \pm 0.7$)$, and Asia (1.2 \pm 0.6$)$. Surprisingly, even though $C T I ®$ is based in Europe and has "International" in its title, it was tied with JOR® (both at 1.2) for the fewest number of collaborating countries compared to BONE® (1.3) and $J B M R \circledR$ (1.4). Although mathematically this was statistically significant, it is likely not meaningfully significant as the differences are so minimal. The percentage change from 1985/1986 to 2015 was very similar for all four journals with respect to the number of institutions and number of countries (Fig. 5a).

An overall increase in the number of references and manuscript length in pages was observed. However, this pattern was not consistent amongst all four journals (Fig. 5b). The increase in the number of references was highest for BONE® (119.2\%), followed by $C T I \circledR(67.0 \%), J B M R \circledR(54.2 \%)$, and $J O R \circledast(48.0 \%)$. There was a very interesting change in the number of manuscript pages over time. Overall, it increased from $6.6 \pm 2.7$ to $8.9 \pm 2.7$ over the last 30 years. However, the percentage change was negative for $J O R \circledR(-3.5 \%)$, while positive for $B O N E \circledast$ (44.8\%), $C T I \circledR(66.7 \%)$, and $J B M R \circledR(33.3 \%)$ (Fig. 5b). Many of these observed changes are likely due to limits levied by the journals on the number of words, references, tables, and figures.

While being first author on a manuscript has benefits in academia, corresponding authorship may be a better indicator of career advancement $[23,37]$. Corresponding authors are often regarded as those who generated the research idea or in whose laboratory the research was conducted, and frequently considered the more senior colleague compared to the first author [25,37]. In this study, we noted that the corresponding author position/location has moved more from the first to the last author position over these 30 years. Costas et al. [23] noted that corresponding author position was also dependent upon the number of authors on a manuscript. This same finding was seen in this study, where the corresponding author position progressively moved from first to last 
as the number of authors increased. This was seen for North America, Asia, and Australia/New Zealand, but not

Europe. It also occurred when the first author was male or female, as well as for male corresponding authors; such a change was not seen when the corresponding author was female.

In recent years, women have been accepted to undergraduate and graduate education programs at similar rates as men [38] and women have made considerable gains in obtaining doctorates in science. Indeed, the number of women obtaining doctorates has more than doubled in the United States since 1980 and is now nearing equity [1]. Women now comprise one-half of all medical students [6]. These gender shifts in medicine, science and engineering should theoretically translate into a greater number of female authors in the future. In this study we found that there was a significant increase in both female first and corresponding authors over time (Figs. 3a and 3b) for all four journals. $C T I \circledR$ consistently had the greatest percentage of female authors (Fig. 3), with the odds of a female first author being approximately 2.5 times that of $J O R \circledast$, a female corresponding author 2.0 times that of $J O R \circledast$, and both first and corresponding authors being female 2.4 times that of $J O R \circledast$. The greatest increase for female first authors by regions was for Australia/New Zealand (25.0\%), followed by Europe (24.6\%), North America (20.4\%), and Asia (8.1\%). For corresponding author, the greatest increase was $22.1 \%$ for Australia/New Zealand, followed by Europe (20.9\%), Asia (14.9\%), and North America (14.3\%). As CTI® is a European based journal, the fact that it is the leader in female authorship is likely due to the fact that Europe had some of the greatest increases in female authorship over time. Conversely, another explanation for differences in female authorship is that $J O R \circledR$ is more closely related to orthopaedic surgery, and it is well known that there is a significant gender disparity in that surgical specialty [39].

There are differences in collaboration patterns by discipline and gender [32], with female scientists having a lower probability of repeating previous co-authors compared to males. Sharing of science is more likely with male scientists [40]. In the US, being highly connected with collaborators correlates with greater success for women than for men in the field of science [41]. Previous studies have shown that women often prefer to be mentored by other women [42]. Assuming that the first author is the learner and the corresponding author the mentor, then the gender combinations we defined can be used to study this question. In this study $59.8 \%$ of the manuscripts had both first and corresponding male authors and $21.2 \%$ had both female authors, likely corroborating the finding of Cullen and Luna [42]. A female first author and male corresponding author accounted for $13.4 \%$ of manuscripts, likely indicating that females are less likely to select a male mentor or that male mentors may be less likely to take on a female mentee. Only 5.6\% of the manuscripts had male first authors and female corresponding authors, perhaps indicating that males rarely choose female mentors in musculoskeletal science, or that fewer senior female mentors exist. When analyzing by journal, $J O R \circledR$ again had a much higher percentage of both authors being male, confirming the known gender disparity in orthopaedic surgery. The other three journals were very similar in gender combinations with more female gender combinations. It has been previously noted that female faculty members in the sciences have a slightly larger number of collaborators than men [43]. In this study, we noted that the number of authors was higher for female first authors, but not corresponding authors (Table 1), supporting the study of Bozeman and Gaughan [43].

\section{Conclusions}


Publication in peer reviewed journals is important for tenure, career advancement, and funding in academia $[8,9,44]$. Our study analyzed authorship and collaboration trends in $C T I 囚$ over the last three decades and compared $C T I \circledR$ to three other major musculoskeletal science journals: $B O N E \AA, J B M R \circledast$, and $J O R \circledast$. With the limitations noted above in mind, all journals demonstrated an increase in the number of authors, number of countries, number of institutions, and number of references over time. All demonstrated an increase in manuscript length except for $J O R{ }^{\circledR}$, which declined. $C T I \circledR$ showed the greatest change in the corresponding author moving from the first to last position over time. All the journals demonstrated an increase in women as both first and corresponding authors, similar to other medical journals [45]; however, $C T I \circledR$ had the highest proportion of women authors. Filardo et. al. [45] noted that the proportion of women first authors has increased significantly in high impact medical journals over the past 20 years, but has plateaued in some journals, and even declined in others. This does not appear to be the case within the field of musculoskeletal science. The gender shifts seen with women receiving more doctorates in science, engineering, and medicine [1-3] has resulted in more women authors in musculoskeletal science. 


\section{Acknowledgements}

The authors acknowledge the work of many individuals that tabulated the data for the three other journals.

These individuals are James P. Fischer, Austin E. Wininger, Elive F. Likine, Andrew S. Gudeman, Alexander R.

Brinker, Jonathan Ryu, Kevin A. Maupin, Faisal Khan, Morgan M. Sandelski, Jeffrey D. Rytlewski, Jennifer Lamb, Christina Pedro, Michael B. N. Adjei, Abhijit Seetharam, Mohammed T. Ali, Christine Y. Wan, Katherine E.

Schultz, and Shatoria Lunsford. 


\begin{abstract}
Author Contributions
RTL, MAK, and ECW designed the study. All authors contributed to the study conduct. AFR, ASG, PB, and PV participated in data collection. Data analysis, interpretation and reporting of the work, as well as initial drafting of the manuscript was conducted by AFR, ASG, RTL, MAK, and ECW. All authors revised the paper critically for intellectual content and approved the final version. All authors agree to be accountable for the work and to ensure that any questions relating to the accuracy and integrity of the paper are investigated and properly resolved. $\mathrm{RTL}$ is responsible for the overall content of the paper and is the guarantor.
\end{abstract}

\title{
Compliance with Ethical Standards
}

Conflict of Interest

The authors declare that they have no conflicts of interest.

\section{Ethical Approval}

Not applicable to this study.

\section{Human and Animal Rights and Informed Consent}

Not applicable to this study. 


\section{References}

1. Shen H. (2013) Mind the gender gap. Nature 495(7439):22-24.

2. Shaw AK, Stanton DE. (2012) Leaks in the pipeline: separating demographic inertia from ongoing gender differences in academia. Proc Roy Soc B 279:3736-3741. doi:10.1098/rspb.2012.0822

3. Leslie S-J, Cimpian A, Meyer M, Freeland E. (2015) Expectations of brilliance underlie gender distributions across academic disciplines. Science 347:262-265.

4. Conti A, Visentin F. (2015) Science and engineering Ph.D. students' career outcomes by gender. PLoS One 10:e0133177. https://doi:10.1371/journal.pone.0133177

5. Salinas PC, Bagni C. (2017) Gender equality from a European perspective: myth and reality. Neuron 96:721729. doi.org/10.1016/j.neuron.2017.10.002

6. Lautenberger DM, Dandar VM, Raezer CL, Sloane RA. (2014) The State of Women in Academic Medicine. The Pipeline and Pathways to Leadership. American Association of Medical Colleges, Washington, DC.

7. Leboy PS, Madden JF. (2012) Limitations on diversity in basic science departments. DNA Cell Biol 31:13651371. doi: $10.1089 /$ dna.2012.1756

8. Halperin EC. (1999) Publish or perish - and bankrupt the medical library while we're at it. Acad Med 74:470472.

9. Neill US. (2008) Publish or perish, but at what cost? J Clin Invest 118:2368.

10. Jagsi R, Guancial EA, Worobey CC, Henault LE, Chang Y, Starr R, Tarbell NJ, Hylek EM. (2006) The "gender gap" in authorship of academic medical literature - a 35-year perspective. N Engl J Med 355:281-287.

11. Larivière V, Ni C, Gingras Y, Cronin B, Sugimoto CR. (2013) Global gender disparities in science. Nature 504:211-213.

12. van der Lee R, Ellemers N. (2015) Gender contribution to personal research funding success in The Netherlands. Proc Nat Acad Sci 112:12349-12353. doi/10.1073/pnas.1510159112

13. Kaatz A, Lee Y-G, Potvien A, Magua W, Filut A, bhattacharya A, Leatherberry R, Zhu X, Carnes M. (2016) Analysis of National Institutes of Health RO1 application critiques, impact, and criteria scores: does the sex of the principal investigator make a difference? Acad Med 91:1080-1088. doi: 10.1097/ACM.0000000000001272 14. Duch J, Zeng XHT, Sales-Pordo M, Radicchi F, Otis S, Woodruff TK, Amaral LAN. (2012) The possible role of resource requirements and academic career-choice risk on gender differences in publication rate and impact. PLoS One 7:e51332(1-11. doi:10.1371/journal.pone.0051332

15. West JD, Jacquet J, King MM, Corell SJ, Bergstrom CT. (2013) The role of gender in scholarly authorship. PLoS One 8:e66212. doi:10.1371/journal.pone.0066212

16. Cislak A, Formanowicz M, Saguy T. (2018) Bias against research on gender bias. Scientometrics 115:189-200. doi.org/10.1007/s11192-018-2667-0

17. Wininger AE, Fischer JP, Likine EF, Gudeman AS, Brinker AR, Ryu J, Maupin KA, Lunsford S, Whipple EC, Loder RT, Kacena MA. (2017) Bibliometric analysis of female authorship trends and collaboration dynamics over $J B M R{ }^{\circledR}$ 's 30-year history. J Bone Miner Res 32:2405-2414. doi: 10.1002/jbmr.3232 
18. Khan F, Sandelski MM, Rytlewski JD, Lamb j, Pedro C, Adjei MBN, Lunsford S, Fischer JP, Wininger AE, Whipple EC, Loder RT, Kacena MA. (2018) Bibliometric analysis of authorship trends and collaboration dynamicsover the past three decades of BONE's publication history. Bone 107:27-35.

https://doi.org.10.1016/j.bone.2017.10.026

19. Seetharam A, Ali MT, Wang CY, Schultz KE, Fischer JP, Lunsford S, Whipple EC, Loder RT, Kacena MA. (2018) Authorship trends in the Journal of Orthopaedic Research: a bibliometric analysis. J Orthop Res in press doi: 10.1002/jor.24054 [Epub ahead of print]

20. Hall KL, Vogel AL, Huang GC, Serrano KJ, Rice EL, Tsakraklides SP, Fiore SM. (2018) The science of team science: A review of the empirical evidence and research gaps on collaboration in science. American Psychology 73:532-548. doi: 10.1037/amp0000319

21. Falk-Krzesinski HJ, Börner K, Contractor N, Fiore SM, Hall KL, Keyton J, Spring B, Stokols D, Trochim W, Uzzi B. (2010) Advancing the science of team science. Clin Transl Sci 3:263-266. doi:10.1111/j.17528062.2010.00223.x

22. Mimouni M, Zayit-Soudry S, Segal O, Barak Y, Nemer AY, Shylman S, Geffen N. (2016) Trends in authorship of articles in major ophthalmology journals by gender, 2002-2014. Ophthalmology 123:1824-1828. doi.org/10.1016/j.ophtha.2017.04.034

23. Costas R, Bordons M. (2011) Do age and professional rank influence the order of authorship in scientific publications? Some evidence from a micro-level perspective. Scientometrics 88:145-161.

24. Mattsson P, Sundberg CJ, Laget P. (2011) Is correspondence reflected in the author position? A bibliometric study of the relation between corresponding author and byline position. Scientometrics 87:99-105. doi:10.1007/s11192-010-0310-9

25. Riesenberg D, Lundberg GD. (1990) The order of authorship: who's on first? JAMA 264:1857.

26. Baerlocher MO, Newton M, Gautam T, Tomlinson G, Detsky AS. (2007) The meaning of author order in medical research. J Invest Med 55:174-180. doi:10.2310/6650.2007.06044

27. Romanovsky AA. (2012) Revised h index for biomedical research. Cell Cycle 11:4118-4121. doi.org/10.4161.cc.22179

28. Shapiro DW, Wenger NS, Shapiro MF. (1994) The contributions of authors to multiauthored biomedical research papers. JAMA 271:438-442.

29. Aboukhalil R. (2014) The rising trend in authorship. The Winnower 2:e141832.26907.

doi:10.15200/winn.141832.26907

30. Parker M, Kingori P. (2016) Good and bad research collaborations: researchers' views on science and ethics in global health research. PLoS One 11:e1063579. doi:10.1371/journal.pone.0163579

31. Warner ET, Carapinha R, Weber GM, Hill EV, Reede JY. (2015) Faculty promotion and attrition: the importance of coauthor network reach at an academic medical center. J Gen Int Med 31:60-67. doi:

10.1007/s116606-015-3463-7 
32. Zeng XHT, Duch J, Sales-Pardo M, Mareira JAG, Radicchi F, Ribeiro HV, Woodruff TK, Amaral LAN. (2016) Differences in collaboration patterns across discipline, career stage, and gender. PLoS Biol 14:e1002573. doi:org/10.1371/journal.pbio.1002573

33. Kovacs J. (2017) Honorary authorship and symbolic violence. Med Health Care Philosoph 20:51-59. doi:10.1007/s11019-016-9722-5

34. Al-Herz W, Haider H, Al-Bahhar M, Sadeq A. (2014) Honorary authorship in biomedical journals: how common is it and why does it exist? J Med Ethics 40:346-348. doi:10.1136/medethics-2012-101311

35. Kwok LS. (2005) The White Bull effect: abusive coauthorship and publication parasitism. J Med Ethics 31:554-556. doi:10.1136/jme.2004.010553

36. Birnholtz JP. (2006) What does it mean to be an author? The intersection of credit, contribution, and collaboration in science. J Am Soc Inf Sci 57:1758-1770. doi:10.1002/asi.20380

37. Bhandari M, Guyatt GH, Kularni AV, Devereaus PJ, Leece P, Bajammal S, Heels-Ansdell D, Busse JW. (2014) Perceptions of authors' contributions are influenced by both byline order and designation of corresponding author. J Clin Epidemiol 67:1049-1054. doi.org/10.1016/j.jclinepi.2014.04.006

38. Organisation for Economic Cooperation and Development (2012) Education at a Glance 2012: OECD Indicators.

39. O'Connor MI. (2016) Medical school experiences shape women students' interest in orthopaedic surgery. Clin Orthop 474:1967-1972. https://doi 10.1007/s11999-016-4830-3

40. Massen JJM, Bauer L, Spurny B, Burgnyar T, Kret ME. (2017) Sharing of science is most likely among male scientists. Sci Rep 7:12927(1-5). doi:10.1038/s41598-017-013491-0

41 Madlock-Brown C, Eichmann D. (2016) The scientometrics of successful women in science. In IEEE/ACM International Conferences on Advances in Social Networks Analysis and Mining (ASONAM); San Francisco, California. p. 654-660

42. Cullen DL, Luna G. (1993) Women mentoring in academe: addressing the gender gap in higher education. Gender Education 5:125-137.

43. Bozeman B, Gaughan M. (2011) How do men and women differ in research collaborations? An analysis of the collaborative motives and strategies of academic researchers. Res Pol 40:1393-1402.

doi:10.1016/j.respol.2011.07.002

44. Lundberg GD. (1998) Writing is all. Lancet 352:898.

45. Filardo G, da Graca B, Sass DM, Pollock BD, Smith EB, Martinez MA-M. (2016) Trends and comparison of female first authorship in high impact medical journals: observational study (1994-2014). BMJ 352:i847. doi.org.10.1136/bmj.i847 


\section{Legends for Figures}

Fig. 1 Differences in corresponding author location a by year, $\mathbf{b}$ by journal, $\mathbf{c}$ by region (AusNZ = Australia/New Zealand, $\mathrm{N} \mathrm{Am}=$ North America), $\mathbf{d}$ by author number, $\mathbf{e}$ by first author gender, $\mathbf{f}$ by corresponding author gender

Fig. 2 Differences by journal for a general geographic region (AusNZ = Australia/New Zealand, N Am = North America), $\mathbf{b}$ within Canada for the four most common provinces, $\mathbf{c}$ within the US for the four most common states, $\mathbf{d}$ within Europe for the four most common countries and e within Asia for the four most common countries. The corresponding p values were: a $p<10^{-6} \mathbf{b} p=0.008$, c $p=0.051, \mathbf{d} p=0.0002$ and e $p=0.003$

Fig. 3 Changes in first and corresponding author gender over time, for all journals as well as by individual journals $\mathbf{a}$ for first author, $\mathbf{b}$ for corresponding author

Fig. 4 Differences in the percentage of manuscripts published based on gender combinations of the first and corresponding authors by a year of publication, $\mathbf{b}$ by journal and $\mathbf{c}$ by region (AusNZ = Australia/New Zealand, $\mathrm{N}$ $\mathrm{Am}=$ North America). These differences were all statistically significant (all $p<0.0001)$

Fig. 5 Percent change from 1985 to 2015 in a the number of authors, number of countries, and number of institutions between the four different journals and $\mathbf{b}$ the number of references and manuscript length in pages 
a

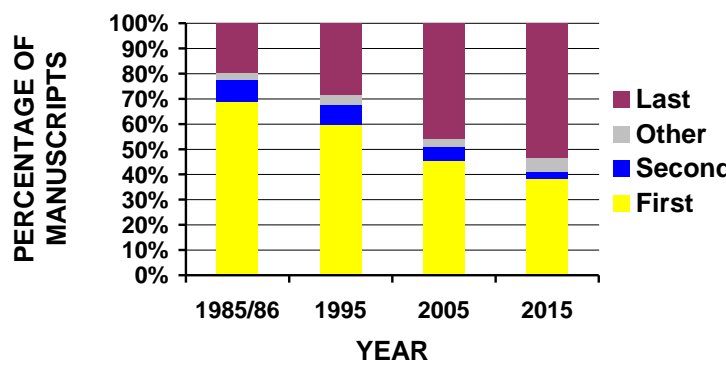

C

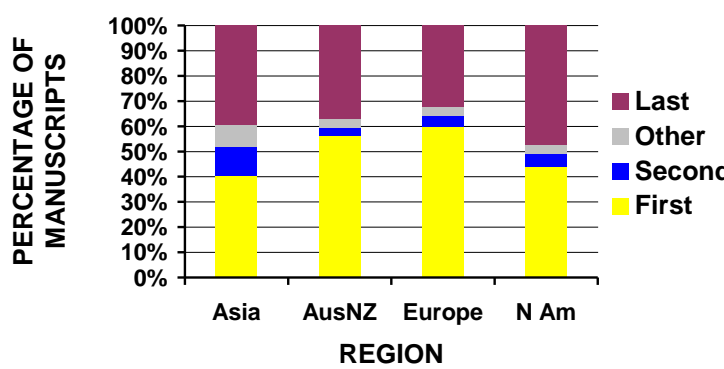

e

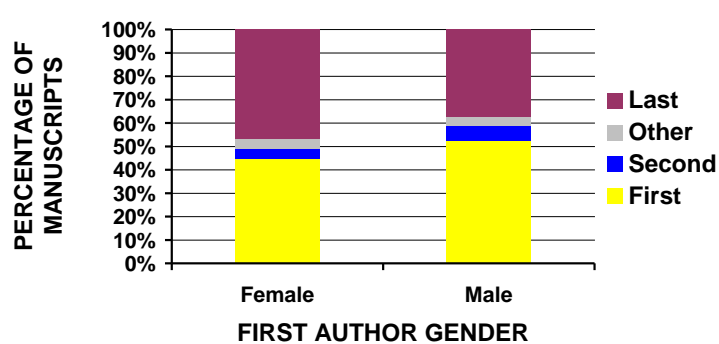

b

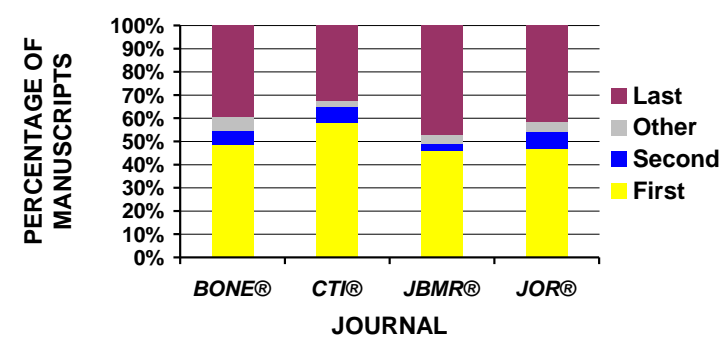

d

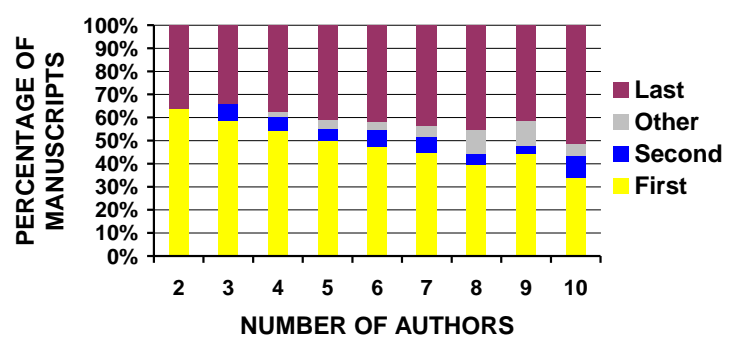

f

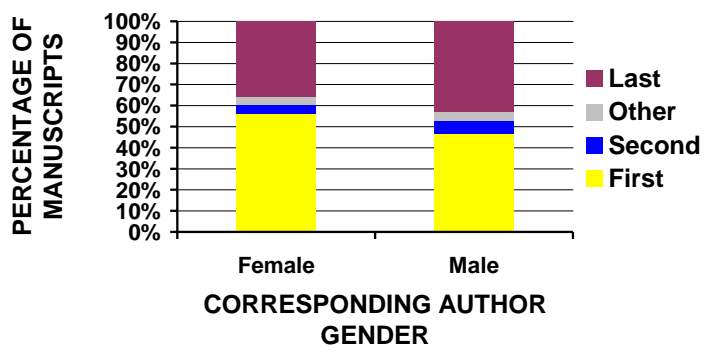


a

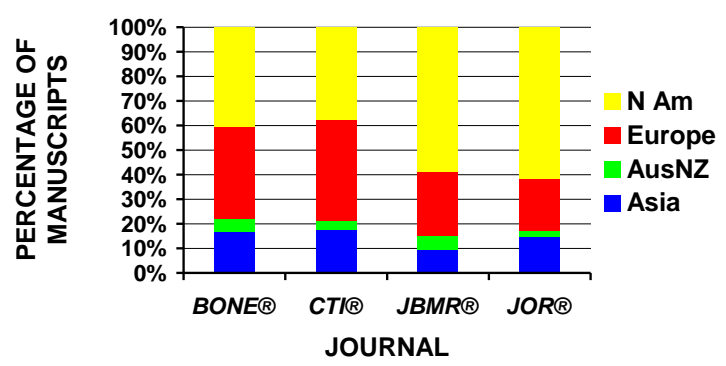

C

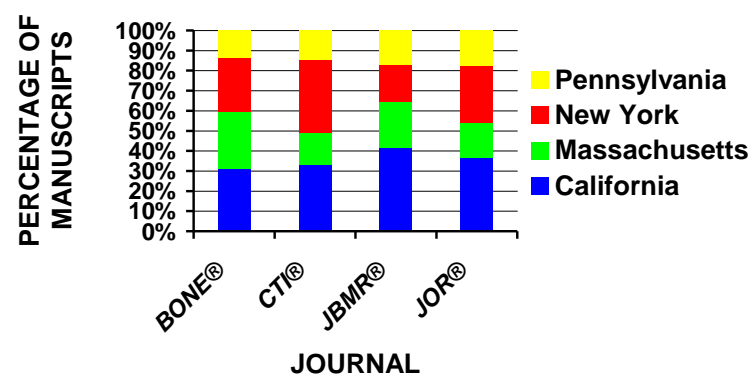

b

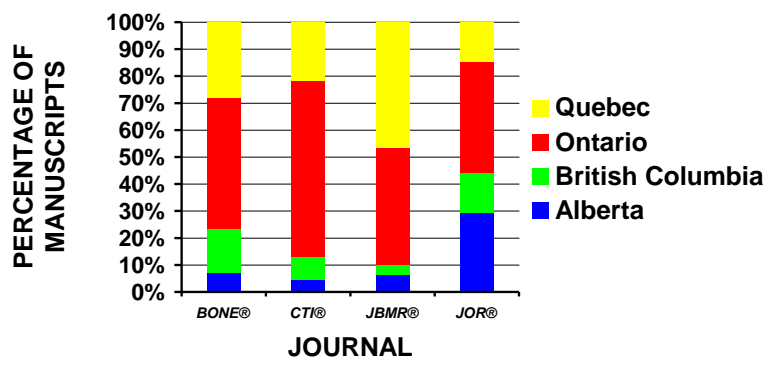

d

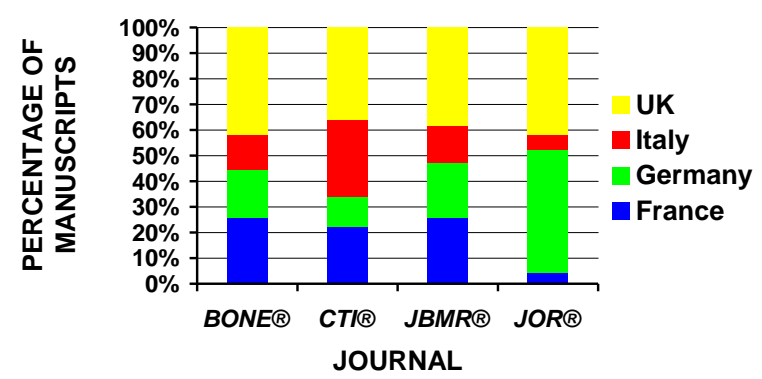

e

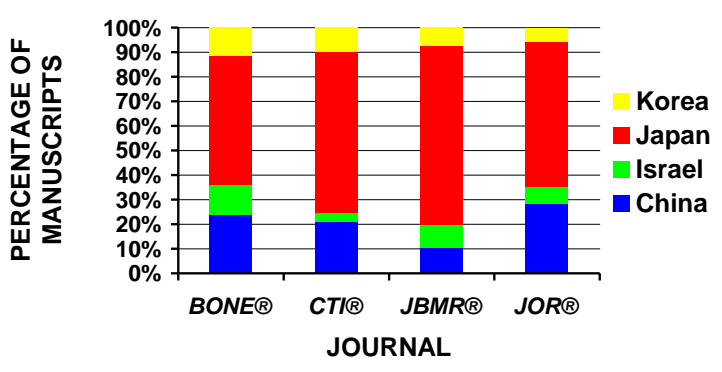


a

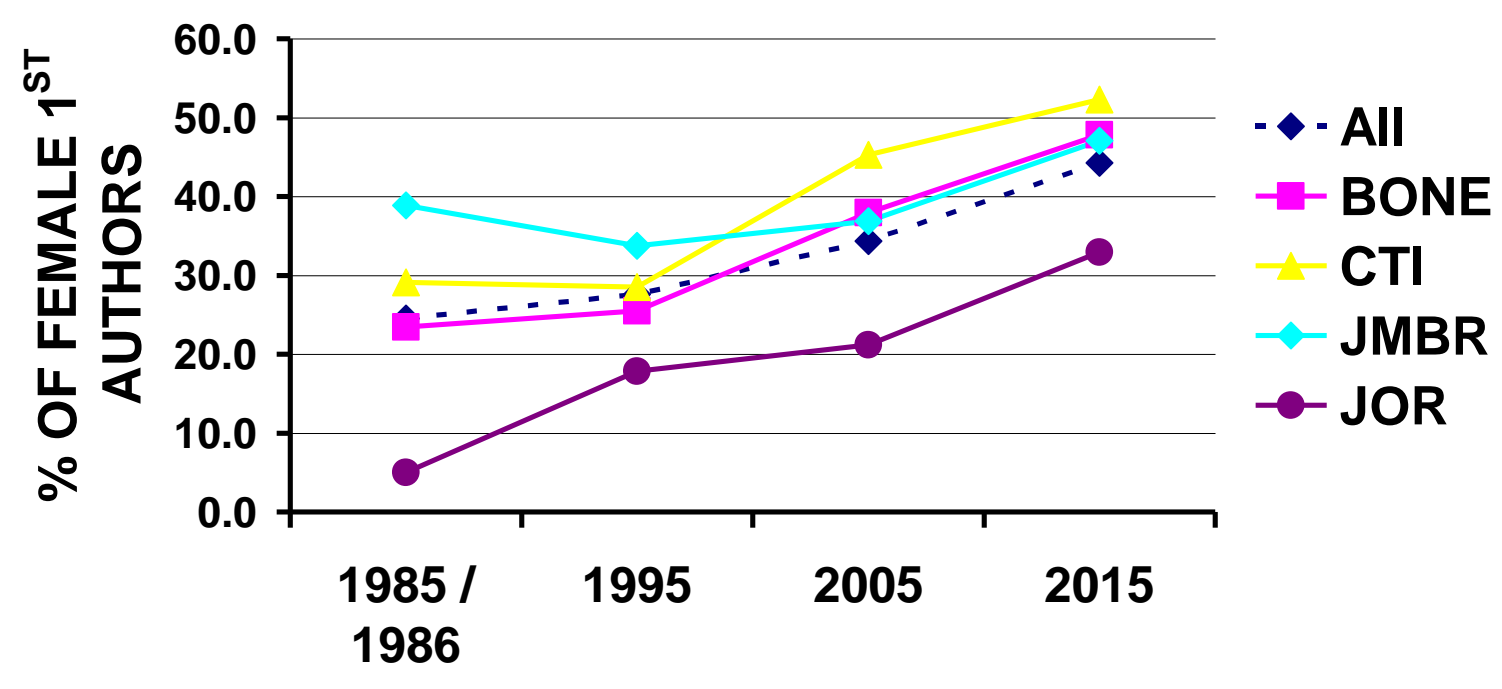

YEAR

b

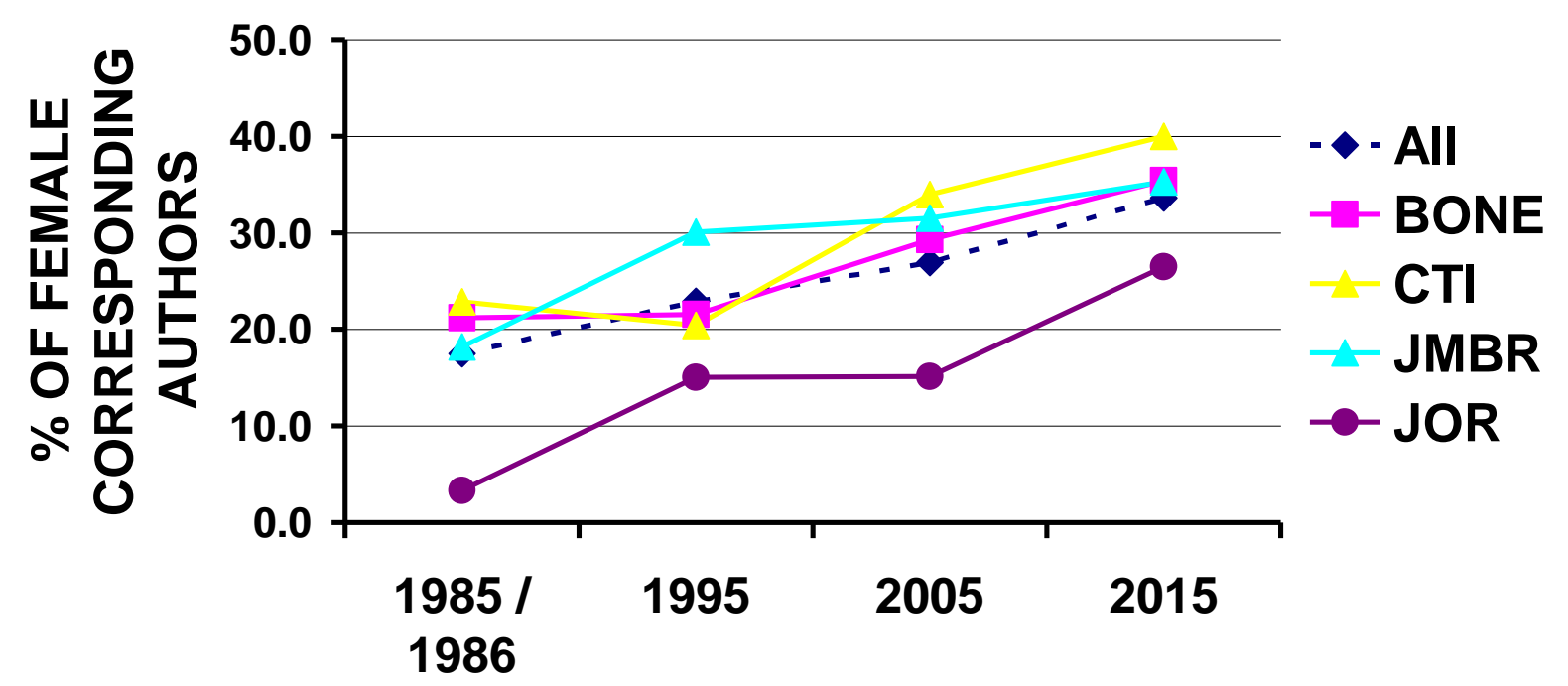

YEAR 
a

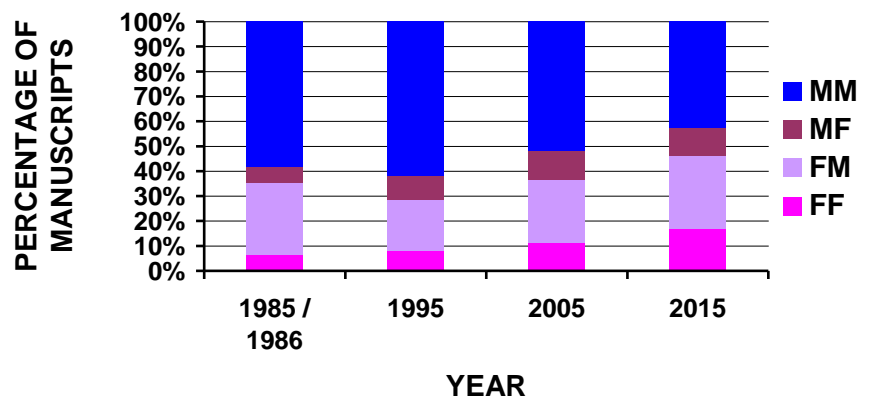

b

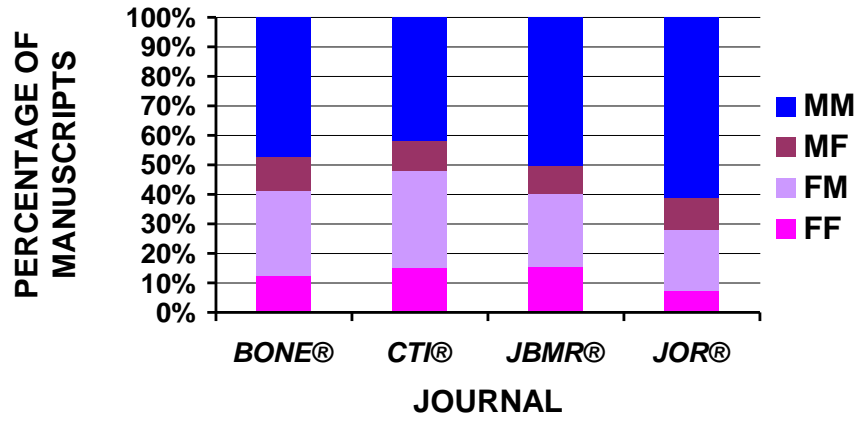

C

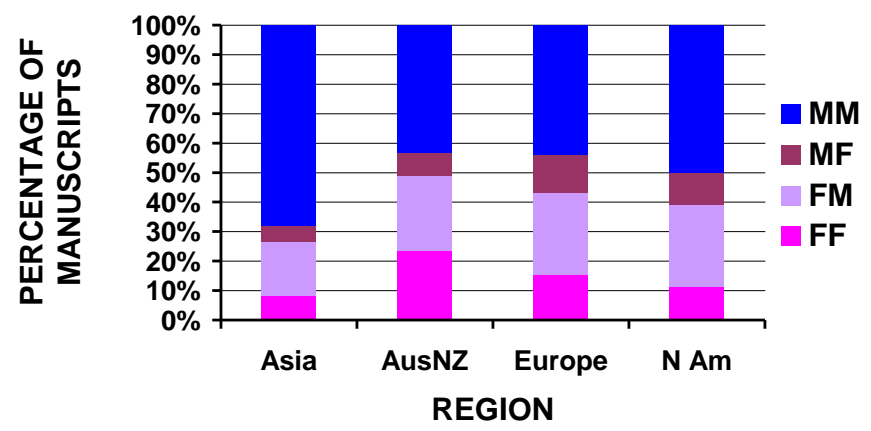


a

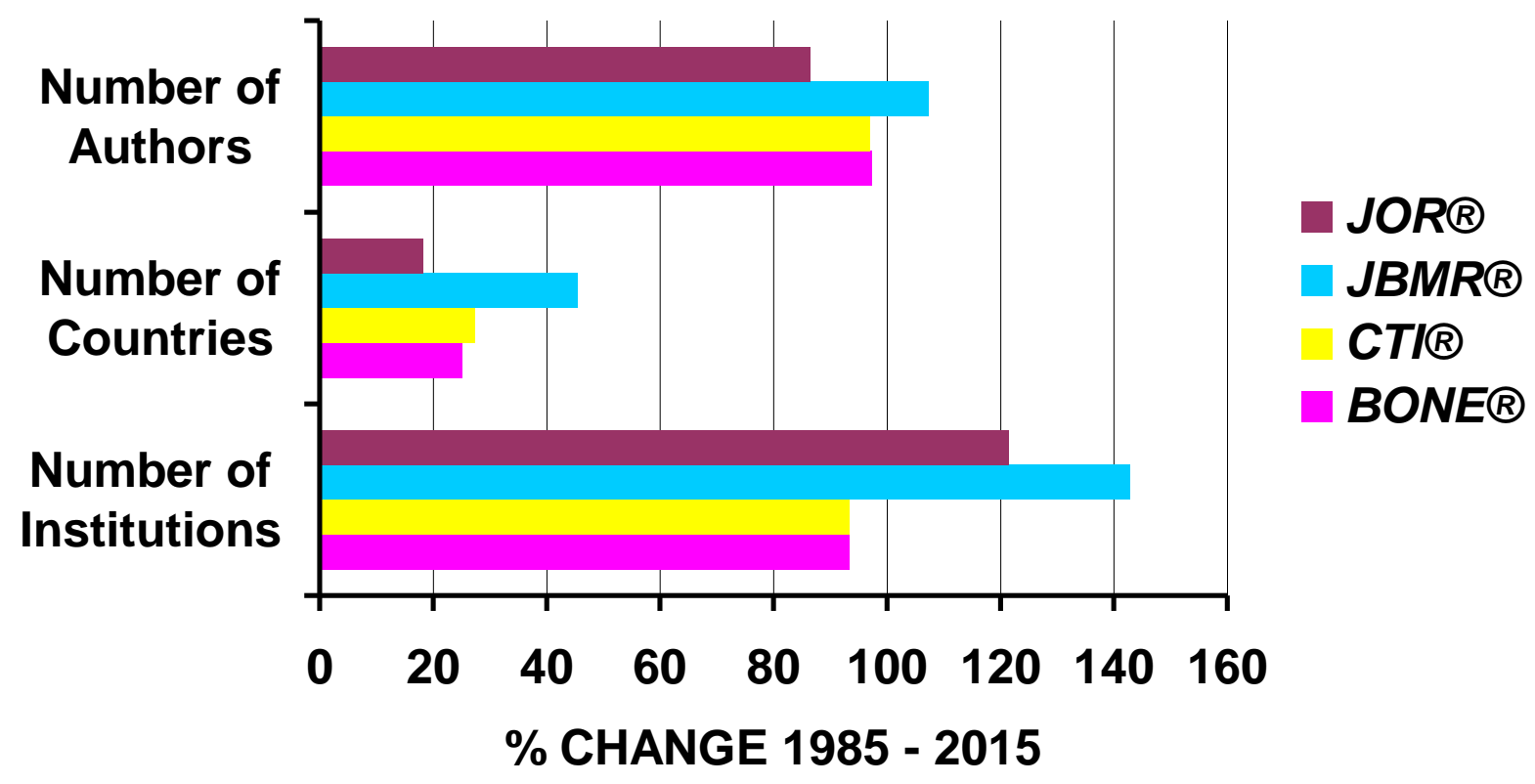

b

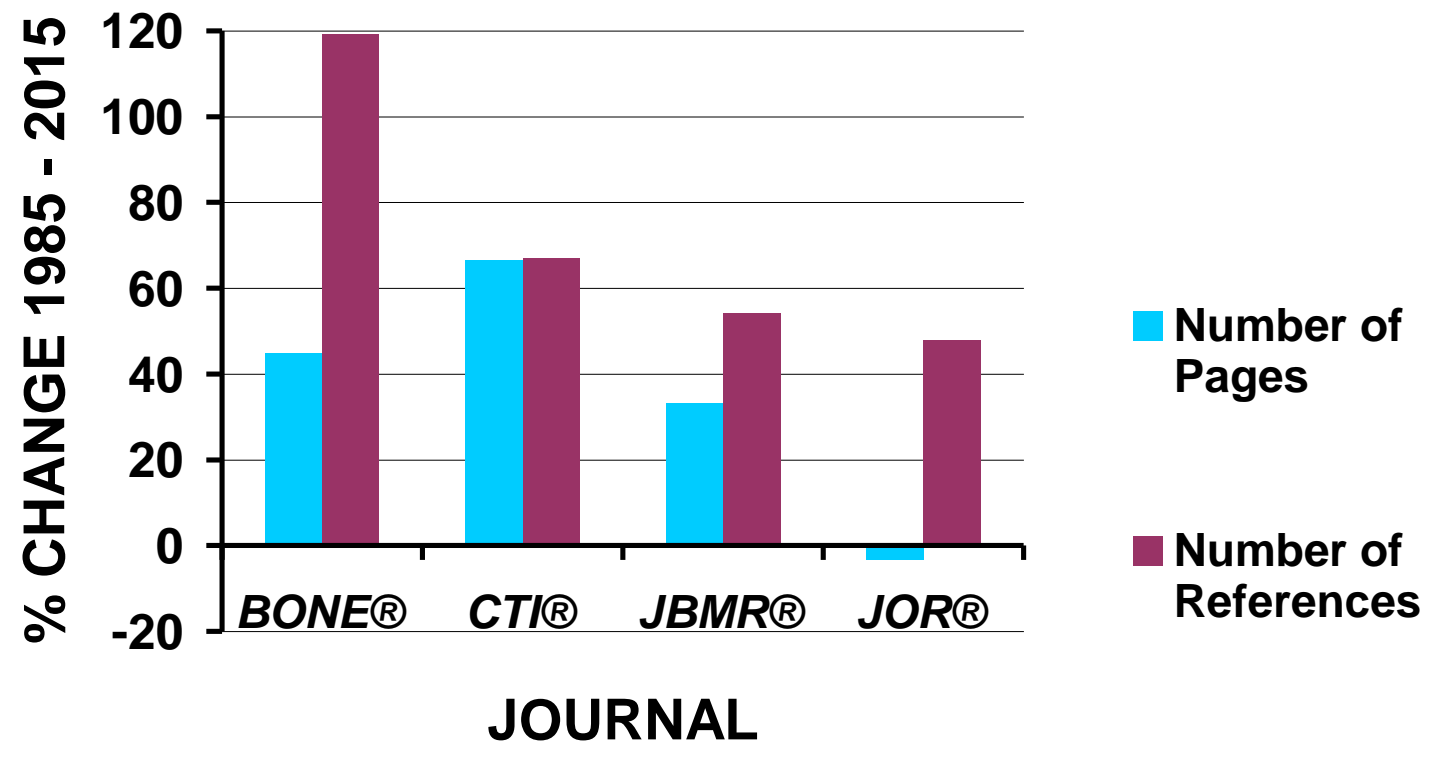


Table 1 Author number, number of countries, and number of institutions between the four musculoskeletal science journals

\begin{tabular}{|c|c|c|c|c|c|c|c|c|c|c|c|c|c|c|c|}
\hline & & & & Author & number & & & & & Num & ber of cou & Intries & & & \\
\hline Variable & $\mathbf{n}$ & All & BONE® & CTI ${ }^{\circledR}$ & $J B M R \circledR$ & JOR ${ }^{\circledR}$ & p value* & All & BONE® & CTI ${ }^{\circledR}$ & $J B M R \AA$ & JOR ${ }^{\circledR}$ & p value* & All & BONE® \\
\hline $\mathbf{n}$ & & 2776 & 899 & 514 & 746 & 617 & - & & 899 & 514 & 746 & 617 & - & & 899 \\
\hline All & 2776 & $5.8 \pm 3.0$ & $5.8 \pm 3.0$ & $4.9 \pm 2.4$ & $6.8 \pm 3.5$ & $5.6 \pm 2.5$ & $<10^{-6}$ & $1.3 \pm 0.8$ & $1.3 \pm 0.8$ & $1.2 \pm 0.5$ & $1.4 \pm 1.0$ & $1.2 \pm 0.5$ & 0.000001 & $2.4 \pm 1.8$ & $2.4 \pm 1.72$ \\
\hline \multicolumn{16}{|l|}{ By Year } \\
\hline & 1985/1986 293 & $3.6 \pm 1.7$ & $3.6 \pm 1.6$ & $3.3 \pm 1.8$ & $4.1 \pm 1.6$ & $3.7 \pm 1.5$ & 0.0092 & $1.1 \pm 0.3$ & $1.2 \pm 0.4$ & $1.1 \pm 0.3$ & $1.1 \pm 0.3$ & $1.1 \pm 0.2$ & 0.088 & $1.4 \pm 0.7$ & $71.5 \pm 0.71$ \\
\hline & 1995798 & $4.7 \pm 2.2$ & $4.4 \pm 2.1$ & $4.5 \pm 2.1$ & $5.4 \pm 2.5$ & $4.5 \pm 1.8$ & 0.00006 & $1.2 \pm 0.6$ & $1.2 \pm 0.4$ & $2.3 \pm 1.6$ & $1.2 \pm 0.8$ & $1.1 \pm 0.3$ & 0.38 & $1.9 \pm 1.2$ & $21.8 \pm 0.81$ \\
\hline & 2005757 & $6.0 \pm 2.6$ & $5.9 \pm 2.3$ & $5.5 \pm 2.4$ & $7.1 \pm 3.2$ & $5.2 \pm 2.0$ & $<10^{-6}$ & $1.4 \pm 0.9$ & $1.4 \pm 1.0$ & $1.3 \pm 0.6$ & $1.5 \pm 1.1$ & $1.2 \pm 0.4$ & 0.00027 & $2.4 \pm 1.7$ & $72.4 \pm 1.72$ \\
\hline & 2015928 & $7.3 \pm 3.5$ & $7.1 \pm 3.6$ & $6.5 \pm 2.7$ & $8.5 \pm 5.6$ & $6.9 \pm 2.7$ & 0.000001 & $1.4 \pm 0.9$ & $1.5 \pm 0.9$ & $1.4 \pm 0.6$ & $1.6 \pm 1.2$ & $1.3 \pm 0.6$ & 0.0072 & $3.1 \pm 2.3$ & $32.9 \pm 2.02$ \\
\hline & p value ${ }^{\wedge}-$ & $<10^{-6}$ & $<10^{-6}$ & $<10^{-6}$ & $<10^{-6}$ & $<10^{-6}$ & & $<10^{-6}$ & 0.0003 & 0.0018 & $<10^{-6}$ & 0.00036 & & $<10^{-6}$ & $<10^{-6}$ \\
\hline \multicolumn{16}{|c|}{ By 1st Author Gender } \\
\hline & M 1766 & $5.6 \pm 3.0$ & $5.4 \pm 2.9$ & $4.6 \pm 2.4$ & $6.7 \pm 3.4$ & $5.5 \pm 2.5$ & $<10^{-6}$ & $1.3 \pm 0.7$ & $1.3 \pm 0.7$ & $1.2 \pm 0.5$ & $1.5 \pm 1.0$ & $1.2 \pm 0.5$ & $<10^{-6}$ & $2.3 \pm 1.7$ & $72.2 \pm 1.51$ \\
\hline & F 939 & $6.2 \pm 3.2$ & $6.3 \pm 3.2$ & $5.2 \pm 2.5$ & $6.9 \pm 3.7$ & $5.7 \pm 2.2$ & $<10^{-6}$ & $1.3 \pm 0.7$ & $1.4 \pm 0.8$ & $1.2 \pm 0.5$ & $1.3 \pm 0.9$ & $1.2 \pm 0.4$ & 0.082 & $2.5 \pm 2.0$ & $2.6 \pm 1.62$ \\
\hline & p value $^{\wedge} \quad-$ & 0.000005 & 0.00002 & 0.023 & 0.56 & 0.32 & & 0.95 & 0.46 & 0.39 & 0.011 & 0.91 & & 0.00001 & 0.00001 \\
\hline
\end{tabular}

\section{By Corresponding Author Gender}

M $19835.7 \pm 2.95 .6 \pm 2.94 .8 \pm 2.46 .7 \pm 3.3 \quad 5.6 \pm 2.6 \quad<10^{-6} \quad 1.3 \pm .07 \quad 1.3 \pm 0.7 \quad 1.2 \pm 0.5 \quad 1.4 \pm 1.0 \quad 1.2 \pm 0.5 \quad 0.0000012 .3 \pm 1.72 .3 \pm 1.52$

$\begin{array}{llllllllllllllll}\text { F } 733 & 6.0 \pm 3.3 & 6.1 \pm 3.1 & 5.0 \pm 2.6 & 6.9 \pm 3.9 & 5.2 \pm 2.1 & 0.000001 & 1.3 \pm 0.9 & 1.4 \pm 1.0 & 1.2 \pm 0.4 & 1.3 \pm 1.0 & 1.2 \pm 0.4 & 0.088 & 2.6 \pm 2.1 & 2.6 \pm 1.9 & 2.0 .0003\end{array}$

By Region
p value ` $^{-1}$
$0.11 \quad 0.023$
$0.46 \quad 0.032$
0.15
0.52
0.60
0.90
$0.016 \quad 0.79$
0.00020 .0003

North America $13635.5 \pm 3.1 \quad 5.4 \pm 3.24 .0 \pm 2.1 \quad 6.5 \pm 3.5 \quad 5.3 \pm 2.4 \quad<10^{-6} \quad 1.2 \pm 0.7 \quad 1.2 \pm 0.5 \quad 1.2 \pm 0.4 \quad 1.4 \pm 1.0 \quad 1.2 \pm 0.4 \quad 0.0004 \quad 2.2 \pm 1.8 \quad 2.2 \pm 1.4 \quad 1$

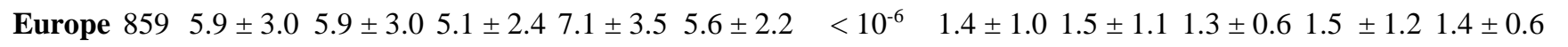

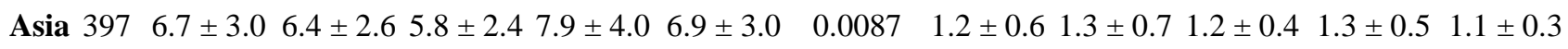
Australia/New Zealand $124 \quad 5.7 \pm 2.4 \quad 5.1 \pm 2.2 \quad 6.6 \pm 2.6 \quad 6.4 \pm 2.5 \quad 4.3 \pm 1.0 \quad 0.0016 \quad 1.3 \pm 0.51 .2 \pm 0.4 \quad 1.1 \pm 0.2 \quad 1.4 \pm 0.6 \quad 1.2 \pm 0.6$ p value $^{\wedge}-<10^{-6} \quad 0.00001 \quad<10^{-6} \quad 0.0068 \quad 0.000001$ $\begin{array}{lllll}10^{-6} & 0.0003 & 0.098 & 0.062 & 0.0007\end{array}$
$74 \quad 2.5 \pm 2.02 .6 \pm 2.12$
$0.24 \quad 2.4 \pm 1.62 .4 \pm 1.42$ $0.08 \quad 2.5 \pm 1.42 .4 \pm 1.22$ $0.0002 \quad 0.045$

\footnotetext{
$*=\mathrm{p}$ value for the row ${ }^{\wedge}=\mathrm{p}$ value for the column
} 
Table 2

Predictors of author gender from multivariate logistic regression analysis

\begin{tabular}{|c|c|c|c|c|c|c|c|c|c|}
\hline \multirow[b]{2}{*}{ Variable } & \multicolumn{3}{|c|}{ Female 1st Author } & \multicolumn{3}{|c|}{$\begin{array}{c}\text { Female Corresponding } \\
\text { Author }\end{array}$} & \multicolumn{3}{|c|}{ Both Authors Female } \\
\hline & OR & $95 \% \mathrm{CI}$ & p value & OR & $95 \% \mathrm{CI}$ & p value & OR & $95 \%$ CI & p value \\
\hline \multicolumn{10}{|l|}{ Journal } \\
\hline CTI@ & 2.52 & $3.33,1.90$ & $<10^{-6}$ & 2.03 & $2.74,1.50$ & 0.000004 & 2.40 & $3.56,1.72$ & $<10^{-6}$ \\
\hline BONE@ & 2.08 & $2.65,1.63$ & $<10^{-6}$ & 1.82 & $2.36,1.40$ & 0.000007 & 1.92 & $2.59,1.43$ & 0.00002 \\
\hline JBMR $₫$ & 2.23 & $2.86,1.74$ & $<10^{-6}$ & 2.06 & $2.68,1.58$ & $<10^{-6}$ & 2.29 & $3.09,1.70$ & $<10^{-6}$ \\
\hline JOR® & $\mathrm{R}$ & - & - & $\mathrm{R}$ & - & - & $\mathrm{R}$ & - & - \\
\hline \multicolumn{10}{|l|}{ Region } \\
\hline North America & 2.22 & $2.93,1.67$ & $<10^{-6}$ & 2.12 & $2.90,1.55$ & 0.000002 & 2.25 & $3.21,1.58$ & 0.000008 \\
\hline Europe & 2.21 & $2.94,1.66$ & $<10^{-6}$ & 2.62 & $3.60,1.90$ & $<10^{-6}$ & 3.09 & $4.42,2.16$ & $<10^{-6}$ \\
\hline Australia/New Zealand & 2.33 & $3.65,1.49$ & 0.0002 & 2.59 & $4.17,1.61$ & 0.00009 & 3.42 & $5.69,2.05$ & 0.000002 \\
\hline Asia & $\mathrm{R}$ & - & - & $\mathrm{R}$ & - & - & $\mathrm{R}$ & - & - \\
\hline \multicolumn{10}{|l|}{ Year } \\
\hline 2015 & 2.91 & $3.99,2.12$ & $<10^{-6}$ & 2.66 & $3.77,1.88$ & $<10^{-6}$ & 2.16 & $3.12,1.49$ & 0.00004 \\
\hline 2005 & 1.79 & $2.47,1.29$ & 0.0004 & 1.83 & $2.61,1.28$ & 0.0009 & 1.38 & $2.02,0.94$ & 0.10 \\
\hline 1995 & 1.16 & $1.60,0.84$ & 0.35 & 1.36 & $1.93,0.95$ & 0.091 & 1.29 & $1.88,0.89$ & 0.18 \\
\hline $1985 / 86$ & $\mathrm{R}$ & - & - & $\mathrm{R}$ & - & - & $\mathrm{R}$ & - & - \\
\hline
\end{tabular}

$\mathrm{OR}=$ odds ratio, $\mathrm{CI}=$ confidence interval, $\mathrm{R}=$ reference value 
Click here to access/download Supplementary Material online resource 1.xls 
Click here to access/download Supplementary Material online resource 2.xls 
Click here to access/download Supplementary Material

\section{online resource 3.doc}


Click here to access/download Supplementary Material online resource 4.doc 
Click here to access/download Supplementary Material online resource 5.doc 